\title{
Stefan Samerski (dir.), Cura animarum. Seelsorge im Deutschordensland Preußen
}

Köln, Weimar, Wien : Böhlau (Forschungen und Quellen zur Kirchen- und Kulturgeschichte Ostdeutschlands, 45), 2013, 249 p., 32,90€

Mathieu Olivier

\section{OpenEdition}

\section{Journals}

Édition électronique

URL : http://journals.openedition.org/ifha/7549

DOI : 10.4000/ifha.7549

ISSN : 2198-8943

Éditeur

IFRA - Institut franco-allemand (sciences historiques et sociales)

Référence électronique

Mathieu Olivier, «Stefan Samerski (dir.), Cura animarum. Seelsorge im Deutschordensland Preußen », Revue de l'IFHA [En ligne], Date de recension, mis en ligne le 13 décembre 2013, consulté le 22 septembre 2020. URL : http://journals.openedition.org/ifha/7549; DOI : https://doi.org/10.4000/ifha. 7549

Ce document a été généré automatiquement le 22 septembre 2020.

C)IFHA 


\section{Stefan Samerski (dir.), Cura animarum. Seelsorge im Deutschordensland Preußen}

Köln, Weimar, Wien : Böhlau (Forschungen und Quellen zur Kirchen- und Kulturgeschichte Ostdeutschlands, 45), 2013, 249 p., 32,90€

\section{Mathieu Olivier}

Le colloque tenu en septembre 2010 dans les murs du couvent d'Oliva près de Gdańsk se proposait de faire le point sur un objet de recherches qui s'est taillé une place de choix dans les travaux sur la Prusse médiévale depuis quelque temps : celui de la pastorale, dans ses aspects les plus concrets et les plus quotidiens. Sous l'égide de "l'Institut pour l'histoire culturelle et ecclésiastique des pays germaniques orientaux ", quatorze historiens allemands et polonais, spécialistes reconnus de la région à l'époque médiévale, ont apporté leur contribution aux débats. Vu depuis la France, ce riche volume d'actes se révèle intéressant à plus d'un titre. À tous ceux qui n'ont pas la possibilité de lire les médiévistes polonais en langue originale, il offre notamment un aperçu commode de travaux importants, telle la thèse de R. Kubicki sur les Dominicains en Prusse au Moyen Âge (2007), ou bien encore la thèse d'habilitation de P. Olinski sur les fondations pieuses dans les villes prussiennes (2008). D'autres contributeurs résument également à grands traits les résultats de leurs recherches, récemment publiées ou bien toujours en cours. Auteur d'une thèse remarquée (et traduite en allemand) sur le diocèse de Sambie, R. Biskup élargit ici son propos à l'ensemble des quatre diocèses prussiens jusqu'en 1525. Sur la base de son volumineux inventaire paru en 2007 (voir Revue de l'IFHA nº 1, p. 383-384), Chr. Hermann revient sur l'architecture des églises prussiennes médiévales, des plus majestueux sanctuaires urbains aux plus modestes édicules ruraux, et les conclusions qu'il est loisible d'en tirer en matière de déploiement de la pastorale dans cette terre de récente christianisation ("L'architecture des églises médiévales dans les diocèses prussiens»). Spécialiste incontestée des manuscrits liturgiques de l'ordre Teutonique, A. Löffler dresse un très utile bilan d'étape de ses propres investigations ( La liturgie de l'ordre Teutonique en Prusse »). Au fil des pages, le lecteur voit en outre se dessiner les contours d'ambitieux 
chantiers scientifiques déjà bien avancés - telle cette base de données sur les paroisses prussiennes médiévales, actuellement en cours d'élaboration à l'Université NicolasCopernic de Toruń (p. 71-73)- ou bien à peine défrichés, à l'instar de l'étude des influences occidentales sur les confréries laïques en Prusse que Kl. Militzer appelle de ses vœux ("L'essor tardif des confréries médiévales dans les terres orientales »). L'angle d'approche retenu dans ce colloque - la pastorale - comporte par ailleurs l'avantage de revisiter de vieilles questions; dans le prolongement d'autres travaux, il oblige à prendre ses distances avec les notions longtemps hégémoniques, et néanmoins peu éclairantes, de «spiritualité » et de « littérature » de l'ordre Teutonique. Signalons à cet égard le propos décapant de C. Hess, qui relativise fortement la spécificité teutonique présumée dans le déploiement du culte marial ( Reine des cieux et maïeuticienne. Le culte marial dans la Prusse de la fin du Moyen Âge »), ainsi que les relectures stimulantes, articulées à la notion de catéchèse, de certaines paraphrase bibliques en langue allemande, reçues sinon produites dans l'ordre Teutonique aux $\mathrm{XIII}^{\mathrm{e}}$ et XIV ${ }^{\mathrm{e}}$ siècles (voir les trois contributions complémentaires d'E. Feistner, «Sur la catéchèse des frères-chevaliers aux premiers temps de l'État teutonique ", "L'État teutonique comme décor littéraire de la catéchèse : 'Le Lituanien' de Schondoch, et de M. Neecke, «Le récit biblique comme fondement de l'identité ? La 'Judith de 1254', sa réinterprétation sauvage et un rédacteur radical»). Le volume pâtit de l'absence de conclusions; tirons-en quelques-unes pour notre propre compte au terme de la lecture : aborder la vie religieuse en Prusse sous l'angle de la pastorale et ses acteurs accompagne assurément l'adieu à un paradigme scientifique exagérément centré sur l'ordre Teutonique et son "identité", envisagée sans guère d'égards pour les divergences d'une commanderie à l'autre, toujours mieux connues (voir sur ce point les considérations d'A. Löffler). Si elle ne disparaît pas complètement, la spécificité du cas prussien en ressort nettement atténuée. La perspective comparatiste, qui affleure dans les contributions de Militzer, Löffler et Hess mériterait d'être approfondie sur une base plus systématique, point par point. En matière de pastorale également, la Prusse médiévale n'est peut-être pas cette terre exotique, quasi-coloniale, qu'on s'est trop longtemps plu à imaginer.

INDEX

Index chronologique : Mittelalter

Thèmes : Geschichte des Religiösen

\section{AUTEUR}

\section{MATHIEU OLIVIER}

Lycée Dumont-d'Urville, Toulon 